
upstream market power 
Los documentos de trabajo del Ivie ofrecen un avance de los resultados de las investigaciones económicas en curso, con objeto de generar un proceso de discusión previo a su remisión a las revistas científicas. Al publicar este documento de trabajo, el Ivie no asume responsabilidad sobre su contenido.

Ivie working papers offer in advance the results of economic research under way in order to encourage a discussion process before sending them to scientific journals for their final publication. Ivie's decision to publish this working paper does not imply any responsibility for its content.

La Serie AD es continuadora de la labor iniciada por el Departamento de Fundamentos de Análisis Económico de la Universidad de Alicante en su colección "A DISCUSIÓN" y difunde trabajos de marcado contenido teórico. Esta serie es coordinada por Carmen Herrero.

The AD series, coordinated by Carmen Herrero, is a continuation of the work initiated by the Department of Economic Analysis of the Universidad de Alicante in its collection "A DISCUSIÓN", providing and distributing papers marked by their theoretical content.

Todos los documentos de trabajo están disponibles de forma gratuita en la web del Ivie http:/ / www.ivie.es, así como las instrucciones para los autores que desean publicar en nuestras series.

Working papers can be downloaded free of charge from the Ivie website http://www.ivie.es, as well as the instructions for authors who are interested in publishing in our series.

Edita / Published by: Instituto Valenciano de Investigaciones Económicas, S.A.

Depósito Legal / Legal Deposit no.: V-4387-2010

Impreso en España (noviembre 2010) / Printed in Spain (November 2010) 
WP-AD 2010-32

\title{
Endogenous quality choice under upstream market power*
}

\author{
Borja Mesa-Sánchez ${ }^{* *}$
}

\begin{abstract}
This paper analyzes how the existence of upstream market power affects endogenous quality choice in a setting where two downstream firms are locked in a bilateral monopoly with their own input suppliers. The main result is that the degree of product differentiation is reduced as upstream market power increases. This holds under Bertrand and Cournot competition, although differentiation is higher in the former. If competition takes place in a Cournot fashion and downstream firms have no bargaining power at all, they choose no differentiation. I also show the effects of an upstream and a downstream merger. When input suppliers merge to monopoly, the quality choice is not affected by the upstream market power and differentiation always emerges. When the downstream segment is shaped by a monopoly, goods become homogeneous unless input suppliers have weak bargaining power. If input prices are high enough before the downstream merger, a downstream monopoly leads to an increase in social welfare.
\end{abstract}

Keywords: vertical differentiation, endogenous quality choice, horizontal mergers

JEL Classification: L11, L13, L15, L41

\footnotetext{
" Thanks are to be given to my supervisors Ramon Fauli-Oller and Joel Sandonís for their encouragement and guidance. Their contributions were crucial to this work.

*** Mesa-Sánchez. University of Alicante. E-mail: borja@ua.es
} 


\section{Introduction}

Recently, several works have analyzed the strategic behaviour of vertically related industries. Starting with Horn and Wolinsky (1988), some of them study the effects of increases in concentration at the downstream segment on input prices and welfare. Von Ungern-Sternberg (1996), Dobson and Waterson (1997), Chen (2003), Lommerud et al. (2003) and Symeonidis (2008, 2010) find that countervailing power, through a reduction in input prices, may arise welfare when upstream firms have a significant bargaining power and goods are close substitutes. In these works the degree of product differentiation plays a crucial role, however none of them consider its choice by firms, assuming it as exogenous. In my article I extend some of the previous findings to a model of vertical differentiation with endogenous quality choice. As the degree of product differentiation affects input prices, by allowing downstream firms to choose it, they have a new instrument to curb the market power of input suppliers. There exist several examples of how the degree of product differentiation affects input prices. In the food manufacturing industry, the introduction of a low quality brand by leading multinational retailers has forced manufacturers to reduce the price of their products. In the automobile industry, assemblers use the same components in different product lines to enhance their bargaining position at expenses of input suppliers. The threat of shifting production between plants of automobile assemblers has lead to important reductions in wages by trade unions (Peoples et al (1993)). It is easy to see that such threat will be more effective as products become close substitutes.

In this article I consider a successive duopolistic structure within which to study how quality choice is affected by changes in the distribution of the bargaining power in the vertical chain. I also analyze how endogenous quality choice is affected by a merger between upstream firms and a merger between downstream firms.

To deal with the first question, I examine endogenous equilibrium qualities in a setting where two independent input suppliers are locked in a bilateral monopoly with two separate downstream 
firms. ${ }^{1}$ I assume that downstream firms choose qualities, producing a final good by transforming an input supplied by upstream firms. Negotiations between suppliers and downstream firms take place through a linear wholesale price contract specifying a per-unit of input price $w$. The negotiations are modelled as a generalized Nash bargaining problem. I solve the endogenous equilibrium qualities for Bertrand and Cournot competition, and focus on variable costs of quality improvement. The main contribution of this article is to show that downstream firms tend to reduce product differentiation as the bargaining power of input suppliers increases. Furthermore, in the Cournot setting, when upstream firms have all the bargaining power, no differentiation emerges. The intuition is as follows. When input suppliers act independently, they do not take into account how the price of their inputs affects the input demand of their rival. In particular, they do not internalize that an increase in the price of the input has a positive effect on rival's demand. I show how a greater bargaining position of input suppliers leads to an increase in input prices, but as far as this increase is always higher for the input price of the high quality firm (its demand is more inelastic), the low quality producer benefits more from this positive effect, increasing its market share. A greater (smaller) market share for the low (high) quality firm increases (decreases) its marginal profits of quality, being able to choose a higher (lower) quality. This makes narrower the gap of qualities. From other point of view, in this setting input prices become a positive externality for rivals, and this externality is greater for the low quality firm. As input suppliers enhance their bargaining position, the externality on the low quality firm increases with respect to the high quality one, making bigger the loss of market share of the high quality firm in favour of its rival, leading to closer quality choice, and no differentiation when upstream firms have all the bargaining power and competition is à la Cournot. This seems paradoxical because upstream firms would be better off with differentiation, given that input demands become more inelastic. Regardless the increase in the intensity of competition that a higher upstream bargaining

\footnotetext{
${ }^{1}$ Bilateral monopoly may emerge from many sources, such as irreversible R\&D expenditures, high costs of input transportation, or cases in which firms use a unionized labour force
} 
causes, consumer surplus and welfare reduce due to the increase in input prices.

Several works have analyzed the issue of quality competition since the early article by Gabszewicz and Thisse (1979). Some of these articles compare endogenous equilibrium qualities under price and quantity competition. In these models, the degree of quality differentiation depends on the nature of the competition and the assumptions about the costs of quality. ${ }^{2}$ Motta (1993) considers a model where only two firms operate in the market. At the first stage they choose qualities and, in the second stage, they compete in the final market. Motta analyzes Bertrand and Cournot competition by using two different settings, where firms have fixed or variable costs of quality improvement. Given that no exogenous upper bound for quality is assumed, his model generalizes previous results in the literature of this topic. I take his model to examine how quality choice by downstream firms is affected by the presence of input suppliers. Thus, I can embed his results on mine when upstream firms have no bargaining power. Motta (1993) obtains that firms always differentiate their products, being the degree of product differentiation and social welfare higher under Bertrand competition. These results hold in my model unless competition takes place on quantities and downstream firms have no bargaining power at all, where no differentiation emerges. I also examine the effects of two types of mergers; mergers between upstream firms and mergers between downstream firms. As far as I know, the effects that an upstream and a downstream merger have on the quality choice has not been analyzed before. If the two input suppliers merge, they are able to coordinate their actions, internalizing all the effects that prices cause on the demands of downstream firms. As a result, input prices reduce output and profits of the downstream firms in the same proportion, without affecting the quality choice. In fact, the choice is the same than with no upstream firms (Motta (1993)). As downstream firms differentiate their products more than in the situation with independent input suppliers, their demands become more

\footnotetext{
2 There are two canonical cases about costs in the literature of this topic. Fixed costs of quality improvement, such as investments in R\&D [Shaked and Sutton $(1982,1983,1984)$, Bonanno (1986)], or variable costs associated to skilled labour [Mussa and Rossen (1978), Gal-Or (1983), Champsaur and Rochet (1989)]. I use variable costs and refer to these papers for a discussion of its relevance. As the main result of this paper is that the degree of product differentiation reduces with upstream market power, and it depends on the non-internalized effects of input suppliers, I do not think this main result changes by assuming fixed costs of quality improvement.
} 
inelastic and the monopolist set higher prices. The new entity serves both downstream firms, and the merger is always profitable. A similar result can be found in Horn and Wolinsky (1988), and Milliou and Petrakis (2007), where input prices are set also by bargaining but in a model of horizontal differentiation.

Finally, it is shown that a downstream merger leads to an increase in the responsiveness of the input demands, forcing input suppliers to set lower prices. It is due to the fact that the downstream monopolist is able to increase the production of one good to the detriment of the other, threatening input suppliers by reducing their input demand. As far as the quality choice is endogenous, and the replacing between goods becomes easier when the degree of product differentiation is lower, the downstream monopolist faces a trade-off: either differentiating the products to increase the number of consumers, or getting a reduction in input prices by closing the gap between qualities. We will see how the second factor prevails and goods become homogeneous unless the bargaining position of input suppliers is sufficiently weak. Inderst and Shaffer (2007) also obtain that a downstream merger reduces the degree of product differentiation by analyzing the impact of retail mergers on product variety. They find that a merger may create an incentive for the retailer to force suppliers to compete to become the exclusive supplier. As a result suppliers reduce differentiation to fit the characteristics of their products to consumers preferences in two different markets. Product variety is also reduced, decreasing social welfare. In my model, conversely to Inderst and Shaffer (2007), the downstream monopolist always finds profitable to buy inputs from both upstream firms, and social welfare increases whenever input prices are high enough before the merger, given that the reduction in such input prices will be transmitted to consumers.

The rest of the article is organized as follows. In section 2, I present the model and solve for the equilibrium of the downstream industry, under Bertrand and Cournot competition. In section 3, I solve the model for the case of independent suppliers and for both types of competition. In section 4, the case of an upstream merger is analyzed for Cournot competition. I do the same in section 5 for a downstream merger. Section 6 concludes. All the proofs are relegated to an Appendix. 


\section{The Model}

\subsection{Consumers}

Consider a unit mass of consumers, whose tastes are described by parameter $\theta \in[\underline{\theta}, \bar{\theta}]$, uniformly distributed with unit density. In accordance with the literature, it is assumed that consumers either buy one unit of the good, or buy nothing. The utility function is the Mussa and Rosen (1978) type. If consumers purchase good $i$, their utility is $U=\theta \nu_{i}-p_{i}$, where $\nu_{i}$ and $p_{i}$ represent the quality and the price of the good $i$, respectively. Given any price $p$, a higher $\nu$ means a higher utility for consumers, which are willing to pay more for such a quality. If consumers do not buy the good their utility is zero. It is assumed that they can buy two different goods, good $H$ with quality $\nu_{H}$, and good $L$ with quality $\nu_{L}$, where $\nu_{H}>\nu_{L}$, and prices $p_{H}$ and $p_{L}$, respectively. Hence, $\theta_{H L}=\frac{p_{H}-p_{L}}{\nu_{H}-\nu_{L}}$ is the taste parameter of the indifferent consumer between buying good $H$ and $L$, and $\theta_{L \varnothing}=\frac{p_{L}}{\nu_{L}}$ between buying $L$ and nothing. If a consumer has a taste parameter between $\bar{\theta} \geq \theta \geq \theta_{H L}$ she will buy good $H$, whereas she will buy good $L$ when $\theta_{H L}>\theta \geq \theta_{L \varnothing}$. Finally, she will not buy at all when $\theta<\theta_{L \varnothing}$. Given these consumers' preferences, the demand functions are:

$$
\begin{gathered}
q_{H}=\bar{\theta}-\frac{p_{H}-p_{L}}{\nu_{H}-\nu_{L}} \\
q_{L}=\frac{p_{H}-p_{L}}{\nu_{H}-\nu_{L}}-\frac{p_{L}}{\nu_{L}}
\end{gathered}
$$

\section{$2.2 \quad$ Firms}

I consider a two-tier industry consisting of two downstream firms, $H$ and $L$, producing differentiated products. Firm $H(L)$ does it by using an input $l_{H}\left(l_{L}\right)$, bought at price $w_{H}\left(w_{L}\right)$ to supplier $L_{H}\left(L_{L}\right)$. Therefore, downstream and upstream firms are locked in a bilateral monopoly. Firm $H$ produces the good with high quality $\nu_{H}$, whereas firm $L$ produces the good with lower quality $\nu_{L}$. For simplicity, it is assumed that the cost of producing these inputs is zero. However, downstream firms incur in a variable cost, increasing in quality, $c_{i}=\frac{1}{2} \nu_{i}^{2} \quad i \in\{H, L\}$, to transform the inputs into 
final goods on a one to one basis, $q_{i}=l_{i \in\{H, L\}} \cdot{ }^{3}$

Firms play the following three-stage game.

(i) In the first stage, downstream firms choose qualities. As in Motta (1993), I do not assume an upper bound for the level of quality.

(ii) In the second stage, upstream and downstream firms bargain over the price of the input. They use a linear wholesale price contract where they specify a per-unit of input price $w$. Negotiations are described as a simultaneous generalized Nash bargaining problem. Parameter $\gamma$ captures the bargaining power of the upstream firms, and $1-\gamma$ represents the bargaining power of downstream firms, with $0 \leq \gamma \leq 1$. This implies that each bargaining pair take as given the outcome of the simultaneously-run negotiations of the other bargaining pair.

(iii) In the third stage, two cases are analyzed. Downstream firms setting quantities in the final market, or setting prices. The respective equilibrium concepts are the Cournot and the BertrandNash equilibrium.

The whole game is solved by backward induction using the subgame Nash perfect equilibrium.

\subsection{Cournot competition}

The demand functions [1] and [2] are inverted, obtaining:

$$
\begin{aligned}
p_{H} & =\bar{\theta} \nu_{H}-q_{H} \nu_{H}-q_{L} \nu_{L} \\
p_{L} & =\bar{\theta} \nu_{L}-q_{H} \nu_{L}-q_{L} \nu_{L}
\end{aligned}
$$

where $q_{H}$ and $q_{L}$ are the quantities demanded of the high and low quality good, respectively. The profit function for downstream firms are:

$$
\pi_{i}=\left(p_{i}-c_{i}\right) q_{i}-l_{i} w_{i} \quad i \in\{H, L\}
$$

They choose quantities in order to maximize profits. I introduce equations [3] and [4] in [5]. Given that the production function is $q_{i}=l_{i}$, for simplicity I will use $q$ instead of $l$. Once the first order conditions are derived, I obtain the reaction functions:

\footnotetext{
${ }^{3}$ If it is assumed that upstream firms incur in a variable cost of quality improvement instead of downstream firms, the results of this article do not change.
} 


$$
\begin{aligned}
R_{H}\left(q_{L}\right) & =\frac{\bar{\theta} \nu_{H}-q_{L} \nu_{L}-w_{H}-c_{H}}{2 \nu_{H}} \\
R_{L}\left(q_{H}\right) & =\frac{\bar{\theta} \nu_{L}-q_{H} \nu_{L}-w_{L}-c_{L}}{2 \nu_{L}}
\end{aligned}
$$

From [6] and [7], the input demands are derived:

$$
\begin{gathered}
l_{H}\left(w_{H}, w_{L}\right)=q_{H}\left(w_{H}, w_{L}\right)=\frac{2 \bar{\theta} \nu_{H}-\bar{\theta} \nu_{L}-2 w_{H}+w_{L}-2 c_{H}+c_{L}}{4 \nu_{H}-\nu_{L}} \\
l_{L}\left(w_{H}, w_{L}\right)=q_{L}\left(w_{H}, w_{L}\right)=\frac{\bar{\theta} \nu_{H} \nu_{L}-2 w_{L} \nu_{H}+w_{H} \nu_{L}-2 c_{L} \nu_{H}+c_{H} \nu_{L}}{\left(4 \nu_{H}-\nu_{L}\right) \nu_{L}}
\end{gathered}
$$

where the response of input demands to their own prices is different for both firms:

$$
\left|\frac{\partial l_{H}}{\partial w_{H}}\right|=\frac{2}{4 \nu_{H}-\nu_{L}}<\left|\frac{\partial l_{l}}{\partial w_{l}}\right|=\frac{2}{4 \nu_{H}-\nu_{L}} \frac{\nu_{H}}{\nu_{L}}
$$

As far as $\nu_{H}>\nu_{L}$, the input demand of the low quality firm is more elastic than the input demand of the high quality one. Ceteris paribus, the former firm will face a lower input price than the latter one.

Finally, I derive downstream profits as a function of input prices:

$$
\begin{aligned}
\pi_{H}\left(w_{H}, w_{L}\right) & =\frac{\nu_{H}\left(2 \bar{\theta} \nu_{H}-\bar{\theta} \nu_{L}-2 w_{H}+w_{L}-2 c_{H}+c_{L}\right)^{2}}{\left(-4 \nu_{H}+\nu_{L}\right)^{2}} \\
\pi_{L}\left(w_{H}, w_{L}\right) & =\frac{\left(\left(\bar{\theta} \nu_{H}+w_{H}+c_{H}\right) \nu_{L}-2\left(c_{L}+w_{L}\right) \nu_{H}\right)^{2}}{\nu_{L}\left(-4 \nu_{H}+\nu_{L}\right)^{2}}
\end{aligned}
$$

\subsection{Bertrand competition}

I examine now the same case as before but assuming Bertrand competition in the final market.

Demand functions [1] and [2] are introduced in the profits function of downstream firms (equation [5]). Once the first order conditions are obtained, the reaction functions are:

$$
\begin{gathered}
R_{H}\left(p_{L}\right)=\frac{\bar{\theta}\left(\nu_{H}-\nu_{L}\right)+p_{L}+w_{H}+c_{H}}{2} \\
R_{L}\left(p_{H}\right)=\frac{p_{H} \nu_{L}+w_{L} \nu_{H}+c_{L} \nu_{H}}{2 \nu_{H}}
\end{gathered}
$$

and the input demands:

$$
l_{H}\left(w_{H}, w_{L}\right)=q_{H}\left(w_{H}, w_{L}\right)=\frac{2 \bar{\theta} \nu_{H}^{2}-2 \bar{\theta} \nu_{H} \nu_{L}-w_{H}\left(2 \nu_{H}-\nu_{L}\right)+w_{L} \nu_{H}-2 c_{H} \nu_{H}+c_{L} \nu_{L}+c_{H} \nu_{L}}{\left(4 \nu_{H}-\nu_{L}\right)\left(\nu_{H}-\nu_{L}\right)}
$$




$$
l_{l}\left(w_{H}, w_{L}\right)=q_{L}\left(w_{H}, w_{L}\right)=\frac{\nu_{H}\left(\bar{\theta} \nu_{H} \nu_{L}-\bar{\theta} \nu_{L}^{2}-w_{L}\left(2 \nu_{H}-\nu_{L}\right)-2 c_{L} \nu_{H}+c_{H} \nu_{L}+c_{L} \nu_{L}\right)+w_{H} \nu_{L} \nu_{H}}{\nu_{L}\left(4 \nu_{H}-\nu_{L}\right)\left(\nu_{H}-\nu_{L}\right)}
$$

As in the Cournot setting, the input demand of the low quality firm is more elastic than the input demand of the high quality one:

$$
\left|\frac{\partial l_{H}}{\partial w_{H}}\right|=\frac{2 \nu_{H}-\nu_{L}}{4 \nu_{H}^{2}-5 \nu_{H} \nu_{L}+\nu_{L}^{2}}<\left|\frac{\partial l_{l}}{\partial w_{l}}\right|=\frac{2 \nu_{H}-\nu_{L}}{4 \nu_{H}^{2}-5 \nu_{H} \nu_{L}+\nu_{L}^{2}} \frac{\nu_{H}}{\nu_{L}}
$$

The following expression summarizes that the response of input demands to their prices is greater, in absolute value, under Bertrand competition. This is due to a fiercer competition when firms set prices.

$$
\left|\left(\frac{\partial l_{i}}{\partial w_{i}}\right)^{B}\right|-\left|\left(\frac{\partial l_{i}}{\partial w_{i}}\right)^{C}\right|>0
$$

To conclude, I derive downstream profits as a function of input prices:

$$
\begin{aligned}
\pi_{H}\left(w_{H}, w_{L}\right) & =\frac{\left(\nu_{H}\left(-2 c_{H}+c_{L}-2 w_{H}+w_{L}+2 \bar{\theta} \nu_{H}\right)+\left(c_{H}+w_{H}-2 \bar{\theta} \nu_{H}\right) \nu_{L}\right)^{2}}{\left(-4 \nu_{H}+\nu_{L}\right)^{2}\left(\nu_{H}-\nu_{L}\right)} \\
\pi_{L}\left(w_{1}, w_{2}\right) & =\frac{\nu_{H}\left(2\left(c_{L}+w_{L}\right) \nu_{H}-\left(c_{H}+c_{L}+w_{H}+w_{L}+\bar{\theta} \nu_{H}\right) \nu_{L}+\bar{\theta} \nu_{L}^{2}\right)^{2}}{\left(-4 \nu_{H}+\nu_{L}\right)^{2}\left(\nu_{H}-\nu_{L}\right) \nu_{L}}
\end{aligned}
$$

\section{$3 \quad$ Independent Input Suppliers}

In the second stage of the game, input supplier $L_{H}$ and downstream firm $H$ bargain over the wholesale price $w_{H}$, assuming that the wholesale price $w_{L}$ has been fixed in the simultaneous run negotiations between supplier $L_{L}$ and firm $L$. Negotiations are modelled as a generalized Nash bargaining problem, where $\gamma$ captures the bargaining power of upstream firms, and $1-\gamma$ the bargaining power of downstream firms, with $0 \leq \gamma \leq 1$. The equilibrium is characterized by using the generalized Nash product solution. The profit functions of input suppliers $L_{H}$ and $L_{L}$ are described by:

$$
\pi^{i}=w_{i}\left[l_{i}\left(w_{i}, w_{j}\right)\right] \quad i, j \in\{H, L\} i \neq j
$$

The input supplier $L_{H}$ bargains with the downstream firm $H$ about the wholesale price $w_{H}$. The outcome of the simultaneous run negotiations between upstream firm $L_{L}$ and $L$ is taken as given, 
and I denote such outcome by $\bar{w}_{L}$. Therefore, $w_{H}$ is chosen to maximize the generalized Nash product:

$$
\max _{w_{H}}\left[\pi^{H}\left(w_{H}, \bar{w}_{L}\right)\right]^{\gamma}\left[\pi_{H}\left(w_{H}, \bar{w}_{L}\right)\right]^{1-\gamma}
$$

where $\pi^{H}\left(w_{H}, \bar{w}_{L}\right)$ and $\pi_{H}\left(w_{H}, \bar{w}_{L}\right)$ are upstream and downstream profits, respectively. As firms have no outside option, their disagreement payoffs are zero.

\subsection{Cournot competition}

I introduce equations [11] and [21] into [22]. The first order conditions from [22] are given by the following expressions: ${ }^{4} 5$

$$
\begin{aligned}
\frac{\gamma}{1-\gamma}\left[l_{H}\left(w_{H}, \bar{w}_{L}\right)+w_{H} \frac{\partial l_{H}}{\partial w_{H}}\right]\left[\pi_{H}\left(w_{H}, \bar{w}_{L}\right)\right] & =-\frac{\partial \pi_{H}\left(w_{H}, \bar{w}_{L}\right)}{\partial w_{H}} w_{H}\left[l_{H}\left(w_{H}, \bar{w}_{L}\right)\right] \\
\frac{\gamma}{1-\gamma}\left[l_{L}\left(\bar{w}_{H}, w_{L}\right)+w_{L} \frac{\partial l_{L}}{\partial w_{L}}\right]\left[\pi_{L}\left(\bar{w}_{H}, w_{L}\right)\right] & =-\frac{\partial \pi_{L}\left(\bar{w}_{H}, w_{L}\right)}{\partial w_{L}} w_{L}\left[l_{L}\left(\bar{w}_{H}, w_{L}\right)\right]
\end{aligned}
$$

Rearranging, I obtain the best-reply functions in input prices:

$$
\begin{aligned}
& R_{H}\left(w_{L}\right)=\frac{\gamma\left(2 \bar{\theta} \nu_{H}-\bar{\theta} \nu_{L}+w_{L}+c_{L}-2 c_{H}\right)}{4} \\
& R_{L}\left(w_{H}\right)=\frac{\left(\left(\bar{\theta} \nu_{H}+w_{H}+c_{H}\right) \nu_{L}-2 c_{L} \nu_{H}\right) \gamma}{4 \nu_{H}}
\end{aligned}
$$

where we can observe how input prices depend positively on rivals' ones, as they are strategic complements. If an input supplier decides to increase its input price, its demand will fall, leading to an increase in the rival's input demand, whose price is going to increase.

From [25] and [26] the equilibrium input prices are derived:

$$
\begin{aligned}
w_{H} & =\frac{2 \gamma \nu_{H}\left(4 c_{H}+c_{L}(-2+\gamma)-4 \bar{\theta} \nu_{H}\right)-\gamma\left(c_{H} \gamma+(-4+\gamma) \bar{\theta} \nu_{H}\right) \nu_{L}}{-16 \nu_{H}+\gamma^{2} \nu_{L}} \\
w_{L} & =\frac{\gamma\left(c_{L}\left(8 \nu_{H}-\gamma \nu_{L}\right)+\nu_{L}\left(2 c_{H}(-2+\gamma)-2(2+\gamma) \bar{\theta} \nu_{H}+\gamma \bar{\theta} \nu_{L}\right)\right)}{-16 \nu_{H}-\gamma^{2} \nu_{L}}
\end{aligned}
$$

\footnotetext{
4 These calculations have been performed with the software Mathematica. All second order conditions are met, and it is possible to show that input prices are always positive.

5 The negotiations between input supplier $L_{L}$ and downstream firm $L$ are simultaneous to firms $L_{H}$ and $H$. Equations [12] and [21] are now used to maximize the generalized Nash product.
} 
It can be checked that each input price depends on both qualities. As firms are locked in a bilateral monopoly, input suppliers cannot coordinate their actions, not internalizing the effect that their respective prices have on the rival's demand.

Rearranging equations [23] and [24] input prices can be expressed in the following way:

$$
w_{i}=\left(p_{i}-c_{i}\right) \beta_{i \in\{H, L\}}
$$

where $\beta=\frac{\gamma\left(4 \nu_{H}-\nu_{L}\right)}{2(2+\gamma) \nu_{H}-\gamma \nu_{L}}$. Equation [29] summarizes how input suppliers, as they do not internalize all the effects that their prices cause, fix input prices as a fraction of downstream profits. Now I introduce equation [29] in input demands (equations [8] and [9]). To be more precise, I introduce $w_{H}=\left(p_{H}-c_{H}\right) \beta$ in the input demand of the high quality firm, and $w_{L}=\left(p_{L}-c_{L}\right) \beta$ in the low quality one. Thus, input demands can be re-formulated as a function of the price of the input of the rival:

$$
\begin{aligned}
q_{H}\left(w_{L}\right) & =\left(\frac{2 \bar{\theta} \nu_{H}-\bar{\theta} \nu_{L}-2 c_{H}+c_{L}}{4 \nu_{H}-\nu_{L}}+\frac{w_{L}}{4 \nu_{H}-\nu_{L}}\right) \frac{1}{\delta} \\
q_{L}\left(w_{H}\right) & =\left(\frac{\bar{\theta} \nu_{H} \nu_{L}-2 c_{L} \nu_{H}+c_{H} \nu_{L}}{\left(4 \nu_{H}-\nu_{L}\right) \nu_{L}}+\frac{w_{H}}{\left(4 \nu_{H}-\nu_{L}\right)}\right) \frac{1}{\delta}
\end{aligned}
$$

where $\delta=\frac{2}{2-\gamma}$, with $\delta \in[1,2]$. The greater $\gamma$ the greater the fall in the input demand of both firms. But the key point is that $w_{H}$ affects $q_{H}$ in the same way than $w_{L}$ affects $q_{L}$, precisely $\frac{1}{\delta}$. If we look at the input demands when there are no upstream firms (input prices are zero):

$$
\begin{aligned}
& q_{H}\left(w_{w_{H}=0, w_{L}=0}\right)=\frac{2 \bar{\theta} \nu_{H}-\bar{\theta} \nu_{L}-2 c_{H}+c_{L}}{4 \nu_{H}-\nu_{L}} \\
& q_{L}\left(w_{H}=0, w_{L}=0\right)=\frac{\bar{\theta} \nu_{H} \nu_{L}-2 c_{L} \nu_{H}+c_{H} \nu_{L}}{\left(4 \nu_{H}-\nu_{L}\right) \nu_{L}}
\end{aligned}
$$

and we compare the market share of downstream firms with the presence of upstream firms $\left(w_{i}>0\right), \frac{q_{H}\left(w_{L}\right)}{q_{L}\left(w_{H}\right)}$, and with no upstream firms $\left(w_{i}=0\right), \frac{q_{H}\left(w_{H}=0, w_{L}=0\right)}{q_{L}\left(w_{H}=0, w_{L}=0\right)}$, it can be checked that the difference only depends on the price of the input of the rival. It is also easy to see in equations [30] and [31] that the input price of the rivals expands the demands, becoming a positive externality, but as far as $w_{H}>w_{L}$, the low quality firm will increase its market share to the detriment of the high quality one, with respect to the setting in which there are no upstream firms and input prices are zero [Motta (1993)]. Furthermore, it can be proved that $\frac{\partial\left(w_{H}-w_{L}\right)}{\partial \gamma}>0$; therefore, the higher 
the bargaining power of upstream firms, the higher the positive externality of the low quality firm with respect to the high quality one, and the greater the market share of the former.

Finally, it can be stated the following relation:

$$
\pi_{i}=q_{i}^{2} \nu_{i} \quad i \in\{H, L\}
$$

A greater market share of the low quality firm leads to a greater proportion of profits with respect to the high quality rival. In fact, it can also be proved that $\frac{\partial\left(\pi_{H}-\pi_{L}\right)}{\partial \gamma}<0$. This allows the former to increase its quality whereas the latter is forced to decrease its own.

Finally, I analyze how downstream firms choose qualities. It can be checked how parameter $\gamma$ affects such choice. Their respective profit functions are given by:

$$
\begin{gathered}
\pi_{H}=\frac{(\gamma-2)^{2} \nu_{H}^{3}\left(-16 \bar{\theta} \nu_{H}+8 \nu_{H}^{2}+8 \bar{\theta} \nu_{L}-2 \gamma \bar{\theta} \nu_{L}-\gamma \nu_{H} \nu_{L}-4 \nu_{L}^{2}+2 \gamma \nu_{L}^{2}\right)^{2}}{\left(4 \nu_{H}-\nu_{L}\right)^{2}\left(16 \nu_{H}-\gamma^{2} \nu_{L}\right)^{2}} \\
\pi_{L}=\frac{(\gamma-2)^{2} \nu_{H}^{2} \nu_{L}\left(8 \bar{\theta} \nu_{H}+4 \gamma \bar{\theta} \nu_{H}+4 \nu_{H}^{2}-2 \gamma \nu_{H}^{2}-2 \gamma \bar{\theta} \nu_{L}-8 \nu_{H} \nu_{L}+\gamma \nu_{L}^{2}\right)^{2}}{\left(-4 \nu_{H}+\nu_{L}\right)^{2}\left(-16 \nu_{H}+\gamma^{2} \nu_{L}\right)^{2}}
\end{gathered}
$$

Downstream firms $H$ and $L$ choose their respective qualities $\nu_{H}$ and $\nu_{L}$ in order to maximize $\pi_{H}$ and $\pi_{L}$. Deriving the first order conditions, and taking the values $\gamma=0$ and $\gamma=1$, the quality choice is $\nu_{H}=0.738096 \bar{\theta}, \nu_{L}=0.585576 \bar{\theta}$ and $\nu_{H}=\nu_{L}=\frac{2}{3} \bar{\theta}$, respectively ${ }^{6}$. Proposition 1 summarizes the previous results:

Proposition 1 Under Cournot competition and variable costs of quality improvement, the degree of product differentiation that downstream firms choose reduces as the upstream bargaining power increases. No differentiation only emerges when downstream firms have no bargaining power at all.

\section{Proof Appendix}

A higher $\gamma$ leads to a best position in terms of output for the low quality firm. The margin of profits, and the marginal profit of quality reduces for the high quality firm with respect to the low quality one. Hence, the better position of the low quality firm leads to a closer quality choice. A similar result can be found in Scarpa (1998), where the introduction of a minimum quality standard leads to a reduction of the highest quality in the market. Finally, when upstream firms

\footnotetext{
${ }^{6}$ See Table 1 in the Appendix
} 
have no bargaining power $(\gamma=0)$, the degree of product differentiation is higher than for any positive value of $\gamma$. As $\gamma$ increases, the bargaining power of upstream firms also increases, and they are going to incentive downstream competition through the uneven positive effect that input prices cause on rivals, leading to a lower degree of product differentiation. When $\gamma=1$, and upstream firms have all the bargaining power, downstream firms choose the same quality and the level of competition is maximum.

\subsection{Bertrand competition}

In this setting downstream firms compete in prices. To determine the optimal input price, $w_{H}$, I introduce equations [19] and [21] in [22]. ${ }^{7}$ The first-order conditions are the same than in the Cournot setting (equations [23] and [24]). From them, I obtain the best-reply functions in input prices:

$$
\begin{gathered}
R_{H}\left(w_{L}\right)=\frac{-2 c_{H} \gamma \nu_{H}+c_{L} \gamma \nu_{H}+w_{L} \gamma \nu_{H}+2 \gamma \bar{\theta} \nu_{H}^{2}+c_{H} \gamma \nu_{L}-2 \gamma \bar{\theta} \nu_{H} \nu_{L}}{2\left(2 \nu_{H}-\nu_{L}\right)} \\
R_{L}\left(w_{H}\right)=\frac{-2 c_{L} \gamma \nu_{H}+c_{H} \gamma \nu_{L}+c_{H} \gamma \nu_{L}+w_{H} \gamma \nu_{L}+\gamma \bar{\theta} \nu_{H} \nu_{L}-\gamma \bar{\theta} \nu_{L}^{2}}{2\left(2 \nu_{H}-\nu_{L}\right)}
\end{gathered}
$$

As in the Cournot case, input prices are strategic complements. The equilibrium input prices are as follows:

$$
\begin{aligned}
& w_{H}=\frac{\gamma\left(c_{H}\left(8 \nu_{H}^{2}-(8+\gamma) \nu_{H} \nu_{L}+2 \nu_{L}^{2}\right)+\nu_{H}\left(c_{L}(-2+\gamma)\left(2 \nu_{H}-\nu_{L}\right)-\bar{\theta}\left(\nu_{H}-\nu_{L}\right)\left(8 \nu_{H}+(\gamma-4) \nu_{L}\right)\right)\right)}{-16 \nu_{H}^{2}+\left(16+\gamma^{2}\right)\left(\nu_{H} \nu_{L}\right)-4 \nu_{L}^{2}} \\
& w_{L}=\frac{\gamma\left(c_{L}\left(8 \nu_{H}^{2}-(8+\gamma) \nu_{H} \nu_{L}+2 \nu_{L}^{2}\right)-\nu_{L}\left(2 \bar{\theta}\left(\nu_{H}-\nu_{L}\right)\left((2+\gamma) \nu_{H}-\nu_{L}\right)+c_{H}(\gamma-2)\left(-2 \nu_{H}+\nu_{L}\right)\right)\right)}{-16 \nu_{H}^{2}+\left(16+\gamma^{2}\right)\left(\nu_{H} \nu_{L}\right)-4 \nu_{L}^{2}}
\end{aligned}
$$

Under Bertrand competition, input prices also depend on both qualities. Equation [29] holds, but now $\beta=\frac{\gamma\left(4 \nu_{H}-\nu_{L}\right)}{2(2+\gamma) \nu_{H}-2 \nu_{L}}$. It is easy to check that the value of this parameter is greater under Bertrand competition. In table 1 in the Appendix, it is shown that upstream profits are also higher under price competition. It is due to the fact that under Bertrand competition the stronger competition leads to a higher differentiation, allowing input suppliers to set higher prices, as the reaction of the rival will be softened through this differentiation. The paradox is that upstream

\footnotetext{
7 To determine $w_{L}$, equations [20] and [21] are introduced in [22]
} 
firms, by not internalizing all the effects derived from their input prices, favour a lower degree of product differentiation and lower input prices.

By using equation [29] in input demands (equations [15] and [16]), the result obtained under Cournot competition is replicated. In this setting $w_{H}>w_{L}$, and the low quality firm also improves its market share with respect to its rival:

$$
\begin{aligned}
& q_{H}\left(w_{L}\right)=\left(\frac{2 \bar{\theta} \nu_{H}^{2}-2 \bar{\theta} \nu_{H} \nu_{L}-2 c_{H} \nu_{H}+c_{L} \nu_{L}+c_{H} \nu_{L}}{\left(4 \nu_{H}-\nu_{L}\right)\left(\nu_{H}-\nu_{L}\right)}+\frac{w_{L} \nu_{H}}{\left(4 \nu_{H}-\nu_{L}\right)\left(\nu_{H}-\nu_{L}\right)}\right) \frac{1}{\delta} \\
& q_{L}\left(w_{H}\right)=\left(\frac{\nu_{H}\left(\bar{\theta} \nu_{H} \nu_{L}-\bar{\theta} \nu_{L}^{2}-2 c_{L} \nu_{H}+c_{H} \nu_{L}+c_{L} \nu_{L}\right)}{\nu_{L}\left(4 \nu_{H}-\nu_{L}\right)\left(\nu_{H}-\nu_{L}\right)}+\frac{w_{H} \nu_{H}}{\left(4 \nu_{H}-\nu_{L}\right)\left(\nu_{H}-\nu_{L}\right)}\right) \frac{1}{\delta}
\end{aligned}
$$

The relation between output and profits is as follows:

$$
\begin{gathered}
\pi_{H}=q_{H}^{2}\left(\nu_{H}-\nu_{L}\right) \\
\pi_{L}=q_{L}^{2}\left(\nu_{H}-\nu_{L}\right) \frac{\nu_{L}}{\nu_{H}}
\end{gathered}
$$

As in the Cournot case, the best position of the low quality firm in terms of output, is also obtained in terms of profits. The downstream profits functions, affected by the parameter $\gamma$, are given by:

$$
\begin{gathered}
\pi_{H}=\frac{(\gamma-2)^{2} \nu_{H}^{2}\left(\nu_{H}-\nu_{L}\right)\left(2 \nu_{H}-\nu_{L}\right)^{2}\left(-16 \bar{\theta} \nu_{H}+8 \nu_{H}^{2}+8 \bar{\theta} \nu_{L}-2 \gamma \bar{\theta} \nu_{L}-\gamma \nu_{H} \nu_{L}-2 \nu_{L}^{2}+\gamma \nu_{L}^{2}\right)^{2}}{4\left(4 \nu_{H}-\nu_{L}\right)^{2}\left(16 \nu_{H}^{2}-16 \nu_{H} \nu_{L}-\gamma^{2} \nu_{H} \nu_{L}+4 \nu_{L}^{2}\right)^{2}} \\
\pi_{L}=\frac{(\gamma-2)^{2} \nu_{H}\left(\nu_{H}-\nu_{L}\right)\left(2 \nu_{H}-\nu_{L}\right)^{2} \nu_{L}\left(-8 \bar{\theta} \nu_{H}-4 \gamma \bar{\theta} \nu_{H}-4 \nu_{H}^{2}+2 \gamma \nu_{H}^{2}+4 \bar{\theta} \nu_{L}+6 \nu_{H} \nu_{L}+\gamma \nu_{H} \nu_{L}-2 \nu_{L}^{2}\right)^{2}}{4\left(4 \nu_{H}-\nu_{L}\right)^{2}\left(16 \nu_{H}^{2}-16 \nu_{H} \nu_{L}-\gamma^{2} \nu_{H} \nu_{L}+4 \nu_{L}^{2}\right)^{2}}
\end{gathered}
$$

For $\gamma=0$ the chosen qualities are $\nu_{H}=0.819521 \bar{\theta}$ and $\nu_{L}=0.398722 \bar{\theta}$. For $\gamma=1$ it is not possible to find the equilibrium qualities as a function of $\bar{\theta}$. In table 1 in the Appendix it is shown that for $\bar{\theta}=5$ and $\gamma=1$ differentiation emerges. Furthermore, it can be proved that, for any value of $\bar{\theta}$ and $\gamma=1$, if there exists equilibrium, downstream firms always differentiate their products.

Proposition 2 Under Bertrand competition and variable costs of quality improvement, the degree of product differentiation that downstream firms choose reduces as the upstream bargaining power increases. Downstream firms always choose to differentiate their products, whatever the distribution of the bargaining power.

\section{Proof Appendix}

Due to the fact that downstream firms anticipate the fiercer competition in a Bertrand fashion, the degree of product differentiation increases. In fact, we have seen in equation [18] how input demands are more elastic under Bertrand than under Cournot competition. For $\gamma=0$, the difference between qualities is $0.420799 \bar{\theta}$, while under Cournot represents $0.15252 \bar{\theta}$. When $\gamma=1$, 
the equilibrium in qualities cannot be obtained as a function of $\bar{\theta}$ (however, it can be computed by assigning values to $\bar{\theta}$ ), but it can be proved that, for any value of $\bar{\theta}$, downstream firms do not choose the same qualities.

\subsection{A comparison between Cournot and Bertrand}

In the Appendix, I include a table in which some numerical examples are performed. I do it for the Bertrand and Cournot settings. For a better comparison with Motta's article (1993), a value of $\bar{\theta}=5$ is fixed, the same value he uses. When $\gamma=0$ (no upstream bargaining power), the results coincide in both papers.

In table 1 in the Appendix, it can be checked how a higher upstream bargaining power leads to a lower degree of product differentiation, the main result of this paper. This holds for both Bertrand and Cournot competition, although in the former, for all the values of $\gamma$, differentiation is always greater. Downstream firms anticipate the tougher competition in the final market, and they try to soften such competition through higher differentiation, which prevails even though they have no bargaining power at all $(\gamma=1)$. As we expect, if $\gamma$ increases, input prices go up, increasing upstream profits to the detriment of downstream ones. Nevertheless, the producer surplus increases with $\gamma$, although due to the double marginalization, this increase does not compensate the reduction in consumer surplus, which falls due to the reduction in final output and the increase in final prices. Therefore, social welfare is decreasing in $\gamma$. Under Bertrand competition, the final price of the high quality good is higher than in the Cournot setting, but the opposite happens for the low quality good, whose price is much lower under Bertrand competition. The reason is the lower level of product differentiation that arises under Cournot competition, leading to similar prices between both goods. In both settings, as $\gamma$ increases, the uncovered market becomes greater, as the quality and the price of the low quality good increases. However, the number of consumers who do not buy any good is inferior in the Bertrand setting, due to the higher differentiation. My results only contradict Motta's (1993) when downstream firms compete à la Cournot and they 
do not have any bargaining power. For the rest of analyzed cases, I obtain that firms differentiate their products in order to soften final market competition. As in Motta (1993), the standard result that Cournot equilibrium profits exceed those under Bertrand competition holds. I also coincide with Motta (1993) in the result about social welfare, which is always superior when firms compete à la Bertrand. The main contribution of this article is to show that upstream market power always reduces the degree of product differentiation, given that input suppliers give downstream firms an incentive to compete through input prices, which turn out to be a positive externality for the rival. As the input price of the high quality firm is always higher, the low quality firm benefits from a higher externality, being able to reduce the gap of qualities. When competition is not too tough, in the Cournot case, the behaviour of input suppliers can lead downstream firms to a situation of no differentiation. The paradox is that upstream firms would be better off with a higher level of product differentiation, but setting prices independently they affect the way in which downstream firms choose qualities. In the next section, we will see how an upstream merger allows the monopolist to internalize all the effects derived from input prices. Under coordination, input prices are going to increase, not affecting the quality choice, and decreasing social welfare.

\section{An Upstream Merger}

In this setting, input suppliers can coordinate their actions as they are now horizontally integrated. The last stage of the game does not change, remaining the downstream firms profits expressions equal, but the second stage does. Now, the monopolist, $L_{H L}$, bargains simultaneously and separately with the two independent downstream firms. This assumption is standard in situations with multilateral contracting (Cremer and Riordan (1987), Horn and Wolinsky (1988) and Milliou and Petrakis (2007)). Under this assumption, the bargaining pair $L_{H L}$ and $H$ has an incentive to behave opportunistically during their negotiations, i.e., an incentive to secretly reach a mutually favorable agreement that allows to enhance the competitive position of downstream firm $H$ to the 
detriment of its rival $L$. The rival pair $L_{H L}$ and $L$ anticipate this opportunistic behavior. Following Cremer and Riordan (1987), Horn and Wolinsky (1988) and Milliou and Petrakis (2007) a contract between $L_{H L}$ and $H$ is immune to a bilateral deviation of the pair $L_{H L}$ and $L$, holding the contract with $H$ constant. As in Horn and Wolinsky (1988), Caprice (2006) and Milliou and Petrakis (2007), it is also assumed that $L_{H L}$ and $H$ cannot implement a contract specifying different contract terms in the event of a breakdown in the negotiations between $L_{H L}$ and $L$. The supplier objective function is now:

$$
\pi^{H L}=w_{H}\left[l_{H}\left(w_{H}, w_{L}\right)\right]+w_{L}\left[l_{L}\left(w_{H}, w_{L}\right)\right]
$$

On the other hand, although downstream firms still have no disagreement payoffs, input supplier's are not zero anymore, given that now it has an outside option. If the negotiations between the monopolist and downstream firm $H[L]$ fail, the disagreement payoff of the former will be $\pi_{D}^{H L}\left(\bar{w}_{L}\right)\left[\pi_{D}^{H L}\left(\bar{w}_{H}\right)\right]$ when downstream firm $L[H]$ acts as a monopoly.

The monopolist bargains with downstream firm $H$ about the wholesale price $w_{H}$. The outcome of the simultaneous run negotiations with downstream firm $L$ are taken as given, and I denote such outcome by $\bar{w}_{L}$. Therefore, $w_{H}$ is chosen to maximize the generalized Nash product:

$$
\max _{w_{H}}\left[\pi^{H L}\left(w_{H}, \bar{w}_{L}\right)-\pi_{D}^{H L}\left(\bar{w}_{L}\right)\right]^{\gamma}\left[\pi_{H}\left(w_{H}, \bar{w}_{L}\right)\right]^{1-\gamma}
$$

where $\pi^{H L}\left(w_{H}, \bar{w}_{L}\right)$ and $\pi_{H}\left(w_{H}, \bar{w}_{L}\right)$ are upstream and downstream profits, respectively. $\pi_{D}^{H L}\left(\bar{w}_{L}\right)=$ $\bar{w}_{L} l_{L}\left(\bar{w}_{L}\right)$ with $l_{L}\left(\bar{w}_{L}\right)=\frac{\bar{\theta} \nu_{L}-\bar{w}_{L}}{2 \nu_{L}}$ is the disagreement payoff of the monopolist if downstream firm $L$ also acts as a monopolist. ${ }^{8}$

\subsection{Cournot competition}

I introduce equations [11] and [47] into [48]. The first order conditions from [48] are derived: ${ }^{9}$

$$
\frac{\gamma}{1-\gamma}\left[l_{H}\left(w_{H}, \bar{w}_{L}\right)+w_{H} \frac{\partial l_{H}}{\partial w_{H}}+\bar{w}_{L} \frac{\partial l_{L}}{\partial w_{H}}\right]\left[\pi_{H}\left(w_{H}, \bar{w}_{L}\right)\right]=
$$

\footnotetext{
${ }^{8} \pi_{D}^{H L}\left(\bar{w}_{H}\right)=\bar{w}_{H} l_{H}\left(\bar{w}_{H}\right)$ with $l_{H}\left(\bar{w}_{H}\right)=\frac{\bar{\theta}_{H}-\bar{w}_{H}}{2 \nu_{H}}$ is the disagreement payoff of the upstream firm, if downstream firm $H$ acts as a monopolist.

9 The negotiations between the upstream monopolist and downstream firm $L$ are simultaneous to those with firm $H$. Equations [12] and [47] are now used to maximize the generalized Nash product.
} 


$$
\begin{gathered}
\left.=\left[-\frac{\partial \pi_{H}\left(w_{H}, \bar{w}_{L}\right)}{\partial w_{H}}\right]\left[w_{H} l_{H}\left(w_{H}, \bar{w}_{L}\right)\right]+\bar{w}_{L} l_{L}\left(w_{H}, \bar{w}_{L}\right)-\bar{w}_{L} l_{L}\left(\bar{w}_{L}\right)\right] \\
\frac{\gamma}{1-\gamma}\left[l_{L}\left(\bar{w}_{H}, w_{L}\right)+w_{L} \frac{\partial l_{L}}{\partial w_{L}}+\bar{w}_{H} \frac{\partial l_{H}}{\partial w_{L}}\right]\left[\pi_{L}\left(\bar{w}_{H}, w_{L}\right)\right]= \\
\left.\left.=\left[-\frac{\partial \pi_{L}\left(\bar{w}_{H}, w_{L}\right)}{\partial w_{L}}\right]\left[w_{L} l_{L}\left(\bar{w}_{H}, w_{L}\right)\right]+\bar{w}_{H} l_{H}\left(\bar{w}_{H}, w_{L}\right)\right]-\bar{w}_{H} l_{H}\left(\bar{w}_{H}\right)\right]
\end{gathered}
$$

We can observe that upstream firms internalize now the positive effect that their prices has on rivals, $\bar{w}_{i} \frac{\partial l_{i}}{\partial w_{j}}$. As a result, they set higher prices, which are not going to depend on the quality of the rival anymore. Before the upstream merger, if an input supplier increases the price of the input, its input demand and profits will fall, increasing the input demand and the profits of its rival. However, under upstream coordination, if the monopolist sets a higher price of the input $i$, it recoups the losses of the fall in the demand through the greater demand of input $j .{ }^{10}$ On the other hand, after the merger the monopolist has incentives to serve both downstream firms.

$$
\begin{aligned}
w_{H}^{U M} & =\frac{\gamma\left(\bar{\theta} \nu_{H}-c_{H}\right)}{2} \\
w_{L}^{U M} & =\frac{\gamma\left(\bar{\theta} \nu_{L}-c_{L}\right)}{2}
\end{aligned}
$$

Proposition 3 Under Cournot competition and variable costs of quality improvement, input prices are always higher with an upstream monopolist than in the case of independent input suppliers, $w_{i}^{U M}>w_{i} i=H, L$.

\section{Proof Appendix}

This result can be found in Horn and Wolinsky (1988) in a setting of horizontal differentiation. It can be explained through two effects. The first one is the positive effect that an increase in the price of the input has on rival's demand, just explained before. The second effect has to do with the disagreement payoffs. If the upstream monopolist does not reach an agreement with a downstream firm, it recoups some losses through the increase of output that the other firm obtains acting as a monopolist in the final market. In other words, the fact of having an outside option enhances the bargaining position of the upstream monopolist.

On the other hand, it is easy to check that input prices only depend on their own quality. If I

\footnotetext{
10 When necessary, I use in some variables the superscript UM (upstream merger), to distinguish from the case of independent input suppliers.
} 
introduce input prices into input demands (equations [8] and [9]), I obtain the following expressions:

$$
\begin{aligned}
q_{H}^{U M} & =\left(\frac{2 \bar{\theta} \nu_{H}-\bar{\theta} \nu_{L}-2 c_{H}+c_{L}}{4 \nu_{H}-\nu_{L}}\right) \frac{1}{\delta} \\
q_{L}^{U M} & =\left(\frac{\bar{\theta} \nu_{H} \nu_{L}-2 c_{L} \nu_{H}+c_{H} \nu_{L}}{\left(4 \nu_{H}-\nu_{L}\right) \nu_{L}}\right) \frac{1}{\delta}
\end{aligned}
$$

where $\delta=\frac{2}{2-\gamma}$ and $\frac{1}{\delta}=1$ if $\gamma=0$. Under upstream coordination, input suppliers take into account all the effects derived from prices. The previous expressions show that input prices affect both input demands equal, reducing them in the same fraction, $\frac{1}{\delta}$, and not affecting the market share of downstream firms, given that $q_{H}\left(w_{H}=0, w_{L}=0\right) \frac{1}{\delta}=q_{H}^{U M}$ and $q_{L}\left(w_{H}=0, w_{L}=0\right) \frac{1}{\delta}=q_{L}^{U M}$. On the other hand, as equation [34] still holds, the effect of input prices, $\frac{1}{\delta}$, does not affect the proportion of profits of downstream firms, $\frac{\pi_{H}^{U M}}{\pi_{L}^{U M}}$, and consequently the quality choice.

Finally, I report the downstream profit functions before choosing qualities:

$$
\begin{gathered}
\pi_{H}^{U M}=\frac{\left(4 \bar{\theta} \nu_{H}-2 \nu_{H}^{2}-2 \bar{\theta} \nu_{L}+\nu_{L}^{2}\right)^{2} \nu_{H}(\gamma-2)^{2}}{16\left(-4 \nu_{H}+\nu_{L}\right)^{2}} \\
\pi_{L}^{U M}=\frac{\left(2 \bar{\theta}+\nu_{H}-2 \nu_{L}\right)^{2} \nu_{H}^{2} \nu_{L}(\gamma-2)^{2}}{16\left(-4 \nu_{H}+\nu_{L}\right)^{2}}
\end{gathered}
$$

where $\gamma$ appears as a multiplicative constant, not affecting qualities and consequently the decision of downstream firms about them.

Proposition 4 Under Cournot competition and variable costs of quality improvement, the presence of an upstream monopolist supplying inputs to both downstream firms does not affect the quality choice, whatever the distribution of the bargaining power in the vertical industry. The equilibrium qualities coincides with those under no upstream market power at all.

\subsection{Profitability of the upstream merger}

In this section I analyze whether an upstream merger in this context is profitable. As far as the merger leads to a monopoly, and there is no outsiders ruining its profitability, we expect that upstream firms are willing to merge. The merger will be successful whenever:

$$
\pi^{H L}>\pi^{H}+\pi^{L}
$$

i.e., the joint profits are greater than independent ones; where $\pi^{H L}$ are the upstream monopolist 
profits when downstream firms compete à la Cournot, and $\pi^{H}$ and $\pi^{L}$ are the profits of input suppliers $L_{H}$ and $L_{L}$, respectively, when they set prices independently and competition is à la Cournot. The following expressions show those profits:

$$
\begin{gathered}
\pi^{H}=-\frac{(\gamma-2) \gamma \nu_{H}^{2}\left(-8 \nu_{H}^{2}+\gamma \nu_{H} \nu_{L}-2(\gamma-2) \nu_{L}^{2}+2 \bar{\theta}\left(8 \nu_{H}+(\gamma-4) \nu_{L}\right)\right)^{2}}{2\left(4 \nu_{H}-\nu_{L}\right)\left(-16 \nu_{H}+\gamma^{2} \nu_{L}\right)^{2}} \\
\pi^{L}=-\frac{(\gamma-2) \gamma \nu_{H} \nu_{L}\left(4(2+\gamma) \bar{\theta} \nu_{H}-2(\gamma-2) \nu_{H}^{2}-2 \gamma \bar{\theta} \nu_{L}-8 \nu_{H} \nu_{L}+\gamma \nu_{L}^{2}\right)^{2}}{2\left(4 \nu_{H}-\nu_{L}\right)\left(-16 \nu_{H}+\gamma^{2} \nu_{L}\right)^{2}} \\
\pi^{H L}=-\frac{(\gamma-2) \gamma \overline{\nu_{H}}\left(\overline{\nu_{H}}\left(-2 \bar{\theta}+\overline{\nu_{H}}\right)^{2}+2 \bar{\theta} \overline{\nu_{H} \nu_{L}}-\left(2 \bar{\theta}+\overline{\nu_{H}}\right){\overline{\nu_{L}}}^{2}+{\overline{\nu_{L}}}^{3}\right)}{32 \overline{\nu_{H}}-8 \overline{\nu_{L}}}
\end{gathered}
$$

The inequality of equation [57] always holds, ${ }^{11}$ and it can be summarized in the following proposition:

Proposition 5 Under Cournot competition and variable costs of quality improvement, an upstream merger is always profitable, whatever the distribution of the bargaining power in the vertical industry.

Proof Appendix

In proposition 3 , it was shown how the coordination between upstream firms implies higher input prices, as they internalize the effects that their prices provoke in rivals and their bargaining power enhance through the availability of an outside option. This coordination leads to the profitability of the merger, for any value of $\gamma$ and qualities.

\subsection{Some numerical examples}

The main result reported in table 1 in the Appendix is the fact that, under upstream coordination, the quality choice by downstream firms is not affected by parameter $\gamma$. The values coincide with the situation of no upstream firms in the market (Motta (1993])). Nevertheless, as the monopolist enhances its bargaining power, the price of the inputs increases. It can be checked, according to proposition 3, that input prices are always greater under upstream coordination. As a consequence, upstream profits become also greater, to the detriment of downstream firms, which face higher costs, reducing quantities and increasing final prices. This pushes consumer

\footnotetext{
11 Given that equilibrium qualities when upstream firms act coordinately are always $\overline{\nu_{H}}=0.738096 \bar{\theta}$ and $\overline{\nu_{L}}=0.585576 \bar{\theta}$, I substitute these values in equation [60] to make the comparison easier.
} 
surplus down. The comparison of producer surplus is ambiguous, although social welfare is clearly smaller. The increase in input prices and the double marginalization lead to the fall on welfare. Finally, regardless of the fact that the quality choice does not change with $\gamma$, the value of the indifferent consumers increases with the upstream bargaining power. The increase in final prices makes bigger the uncovered market. As a conclusion, despite of the fact that an upstream merger does not affect qualities, it results clearly anti-competitive: consumer surplus and social welfare diminish, while the number of consumers who do not buy any good increases.

\section{A Downstream Merger}

Now I analyze how horizontal integration in the downstream industry affects the quality choice. Downstream firms become a monopolist, whereas input suppliers act independently. The downstream firms joint profits expression is:

$$
\pi_{H L}=\left(p_{H} q_{H}+p_{L} q_{L}\right)-\left(l_{H} w_{H}+l_{L} w_{L}\right)
$$

\subsection{Cournot competition}

After the downstream merger, I introduce equations [3] and [4] into [61], deriving a sort of reaction functions: $:^{12}$

$$
\begin{aligned}
& R_{H}^{D M}\left(q_{L}\right)=\frac{\bar{\theta} \nu_{H}-2 q_{L} \nu_{L}-w_{H}-c_{H}}{2 \nu_{H}} \\
& R_{L}^{D M}\left(q_{H}\right)=\frac{\bar{\theta} \nu_{L}-2 q_{H} \nu_{L}-w_{L}-c_{L}}{2 \nu_{L}}
\end{aligned}
$$

Both "reaction functions" have changed after the downstream merger, but the magnitude of the change differs. Comparing equations [62] and [63] with the reaction functions before merging (equations [6] and [7]), it can be checked that the slope of the high quality reaction function has

changed from $\frac{1}{2} \frac{\nu_{L}}{\nu_{H}}$ to $\frac{\nu_{L}}{\nu_{H}}$, whereas the change of the low quality one has been greater, from $\frac{1}{2}$ to 1 . The merger increases the product interdependence, but the high quality production is less affected by the low quality one. The new entity is going to contract output, but it finds more profitable

\footnotetext{
12 When it is necessary, I use in some variables the superscript DM (downstream merger), to distinguish from the rest of cases.
} 
to reduce the low quality production in a stronger way. From [62] and [63], input demands are derived:

$$
\begin{gathered}
l_{H}^{D M}\left(w_{H}, w_{L}\right)=q_{H}^{D M}\left(w_{H}, w_{L}\right)=\frac{\bar{\theta}\left(\nu_{H}-\nu_{L}\right)-w_{H}+w_{L}-c_{H}+c_{L}}{2\left(\nu_{H}-\nu_{L}\right)} \\
l_{L}^{D M}\left(w_{H}, w_{L}\right)=q_{L}^{D M}\left(w_{H}, w_{L}\right)=\frac{w_{H} \nu_{L}-w_{L} \nu_{H}-c_{L} \nu_{H}+c_{H} \nu_{L}}{2\left(\nu_{H}-\nu_{L}\right) \nu_{L}}
\end{gathered}
$$

If we pay attention to the low quality input demand, it does not depend on $\bar{\theta}$ anymore. Furthermore, it is easy to see that assuming fixed costs of quality improvement instead of variable costs, and no upstream firms $(\gamma=0)$, the input demand of the low quality firm would be zero, given that the production of the low quality good only depends on production costs. Therefore, the merger leads to a reduction of both goods, more important for the low quality one, whose profitability falls in favour of the high quality good. Another interesting effect derived from the merger is the change on the slope of the input demands. This change is analyzed in expressions [66] and [67]:

$$
\begin{gathered}
\left|\frac{\partial l_{H}^{D M}}{\partial w_{H}}\right|=\frac{1}{2\left(\nu_{H}-\nu_{L}\right)}>\left|\frac{\partial l_{H}}{\partial w_{H}}\right|=\frac{2 \nu_{H}-\nu_{L}}{4 \nu_{H}^{2}-5 \nu_{H} \nu_{L}+\nu_{L}^{2}} \\
\left|\frac{\partial l_{L}^{D M}}{\partial w_{L}}\right|=\frac{\nu_{H}}{2\left(\nu_{H}-\nu_{L}\right) \nu_{L}}>\left|\frac{\partial l_{L}}{\partial w_{L}}\right|=\frac{-2 \nu_{H}+\nu_{L}}{4 \nu_{H}^{2}-5 \nu_{H} \nu_{L}+\nu_{L}^{2}} \frac{\nu_{H}}{\nu_{L}}
\end{gathered}
$$

The downstream merger has increased the responsiveness of the input demands to their prices. The intuition is as follows. Through the merger, the downstream firms have the possibility of threatening input suppliers by replacing sales between goods. The lower the degree of product differentiation, the easier the replacing and the greater the response of the input demands to their prices. In fact, in equations [66] and [67] it can be checked that if $\nu_{L} \rightarrow \nu_{H},\left|\frac{\partial l_{i}^{D M}}{\partial w_{i}}\right| \rightarrow \infty$, forcing input suppliers to set prices at the competitive level. Thus, the downstream monopolist can obtain lower input prices by producing closer qualities.Finally, the equilibrium downstream profits are given by:

$\pi_{H L}\left(w_{H}, w_{L}\right)=\frac{\left(c_{H}+w_{H}\right)^{2} \nu_{H}+\left(\left(c_{H}+w_{H}\right)\left(c_{H}-2 c_{L}+w_{H}-2 w_{L}\right)-2\left(c_{H}+w_{H}\right) \bar{\theta} \nu_{H}+\bar{\theta}^{2} \nu_{H}^{2}\right) \nu_{L}+\bar{\theta}\left(2\left(c_{H}+w_{H}\right)-\bar{\theta} \nu_{H}\right) \nu_{L}^{2}}{4\left(\nu_{H}-\nu_{L}\right) \nu_{L}}$ 


\subsection{Input prices}

As upstream firms act independently, their profits are given by equation [21]. Each input supplier bargains simultaneous and independently with the downstream monopolist, which enjoys now of an outside option. If the negotiations between the monopolist and the input supplier $L_{H}\left[L_{L}\right]$ fails, the disagreement payoff of the monopolist will be $\pi_{L}^{D}\left(\bar{w}_{L}\right)\left[\pi_{H}^{D}\left(\bar{w}_{H}\right)\right]$ when it only sells the low (high) quality good.

The input supplier $L_{H}$ bargains with the downstream monopolist about the wholesale price $w_{H}$. The outcome of the simultaneous run negotiations with upstream firm $L_{L}$ is taken as given, and I denote such outcome by $\bar{w}_{L}$. Therefore, $w_{H}$ is chosen to maximize the generalized Nash product:

$$
\max _{w_{H}}\left[\pi^{H}\left(w_{H}, \bar{w}_{L}\right)\right]^{\gamma}\left[\pi_{H L}\left(w_{H}, \bar{w}_{L}\right)-\pi_{L}^{D}\left(\bar{w}_{L}\right)\right]^{1-\gamma}
$$

where $\pi_{H L}\left(w_{H}, \bar{w}_{L}\right)$ and $\pi^{H}\left(w_{H}, \bar{w}_{L}\right)$ are downstream and upstream profits, respectively. $\pi_{L}^{D}\left(\bar{w}_{L}\right)=$

$p_{L} q_{L}-l_{L}\left(\bar{w}_{L}\right) w_{L}$ with $l_{L}\left(\bar{w}_{L}\right)=\frac{\bar{\theta} \nu_{L}-\bar{w}_{L}}{2 \nu_{L}}$ is the disagreement payoff of the monopolist if it does not reach an agreement with upstream firm $L_{H} \cdot{ }^{13}$

I introduce equations [21] and [68] into [69]. The first order conditions from [69] are derived:

$$
\begin{aligned}
& \left.\frac{\gamma}{1-\gamma}\left[l_{H}\left(w_{H}, \bar{w}_{L}\right)+w_{H} \frac{\partial l_{H}}{\partial w_{H}}\right]\left[\pi_{H L}\left(w_{H}, \bar{w}_{L}\right)-\pi_{L}^{D}\left(\bar{w}_{L}\right)\right]=-\frac{\partial \pi_{H L}\left(w_{H}, \bar{w}_{L}\right)}{\partial w_{H}} w_{H} l_{H}\left(w_{H}, \bar{w}_{L}\right)\right] \\
& \left.\frac{\gamma}{1-\gamma}\left[l_{L}\left(\bar{w}_{H}, w_{L}\right)+w_{L} \frac{\partial l_{L}}{\partial w_{L}}\right]\left[\pi_{H L}\left(\bar{w}_{H}, w_{L}\right)-\pi_{H}^{D}\left(\bar{w}_{H}\right)\right]=-\frac{\partial \pi_{H L}\left(\bar{w}_{H}, w_{L}\right)}{\partial w_{L}} w_{L} l_{L}\left(\bar{w}_{H}, w_{L}\right)\right]
\end{aligned}
$$

and rearranging they can be expressed as:

$$
w_{i}=\frac{\pi_{H L}\left(\bar{w}_{i}, w_{j}\right)-\pi_{j}^{D}\left(\bar{w}_{j}\right)}{-\frac{\partial \pi_{H L}\left(w_{i}, \bar{w}_{j}\right)}{\partial w_{i}}} \frac{\gamma}{1-\gamma}-l_{i}\left(w_{i}, \bar{w}_{j}\right)\left(\frac{\partial l_{i}}{\partial w_{i}}\right)^{-1} \quad i_{i, j=H, L} \quad i \neq j
$$

On the one hand, when goods are not differentiated at all, the profits of the downstream monopolist and its outside option coincide, making zero the first term of the equation. On the other hand, as $\left(\frac{\partial l_{i}}{\partial w_{i}}\right)^{-1}$ also takes the value zero when $\nu_{H}=\nu_{L}$, input suppliers set $w_{i}=0$ when goods are homogeneous. In this case the downstream monopolist can replace production between goods

\footnotetext{
$13 \pi_{H}^{D}\left(\bar{w}_{H}\right)=p_{H} q_{H}-l_{H}\left(\bar{w}_{H}\right) w_{H}$ with $l_{H}\left(\bar{w}_{H}\right)=\frac{\bar{\theta}_{\nu_{H}}-\bar{w}_{H}}{2 \nu_{H}}$ is the disagreement payoff of the monopolist if negotiations with upstream firm $L_{L}$ fail.
} 
perfectly, threatening input suppliers by shifting the demand of inputs to the rival, and forcing them to decrease prices to the competitive level. The equilibrium input prices are: ${ }^{14}$

$$
\begin{aligned}
w_{H}^{D M} & =\frac{\gamma\left(c_{H}\left(2 \nu_{H}-\gamma \nu_{L}\right)+\nu_{H}\left(c_{L}(\gamma-2)+2 \bar{\theta}\left(-\nu_{H}+\nu_{L}\right)\right)\right)}{-4 \nu_{H}+\gamma^{2} \nu_{L}} \\
w_{L}^{D M} & =\frac{\gamma\left(2 c_{L} \nu_{H}+c_{H}(\gamma-2) \nu_{L}-\gamma\left(c_{L}+\bar{\theta} \nu_{H}\right) \nu_{L}+\gamma \bar{\theta} \nu_{L}^{2}\right)}{-4 \nu_{H}+\gamma^{2} \nu_{L}}
\end{aligned}
$$

This ability of the downstream monopolist to threaten input suppliers by shifting production leads to the following result:

Proposition 6 Under Cournot competition and variable costs of quality improvement, a downstream merger always leads to a fall in input prices, $w_{i}^{D M}<w_{i} i=H, L$.

Proof Appendix

This result is not new. It can be found in Horn and Wollinsky (1988), Dobson and Waterson (1997), Lommerud et al (2003) and Symeonidis (2008, 2010). They work with settings of horizontal differentiation, where the degree of product differentiation is exogenous. Inderst and Shaffer (2007) construct a model where a downstream merger forces suppliers to compete to become the exclusive supplier in two different markets. Thus, the downstream monopolist decides to drop production of one of the goods and reduce variety. Reductions in prices are based on a single-sourcing policy. The degree of product differentiation is also reduced by suppliers to suit the characteristics of their product to consumers preferences in both markets. In my setting the downstream monopolist obtains a reduction in input prices by increasing the demand of one of the inputs to the detriment of the other. By choosing similar qualities the shifting between input demands becomes easier, forcing suppliers to compete fiercer. Therefore, the greater the upstream bargaining power (higher input prices), the greater the incentives of the merging firm to choose closer qualities. Proposition 7 summarizes this fact, but before I report the downstream profits function before choosing qualities:

$$
\begin{aligned}
& \pi_{H L}=\frac{(\gamma-2)^{2} \nu_{H}^{2}\left(16 \bar{\theta}^{2} \nu_{H}-16 \bar{\theta} \nu_{H}^{2}+4 \nu_{H}^{3}+16 \gamma \bar{\theta}^{2} \nu_{L}+4 \gamma^{2} \bar{\theta}^{2} \nu_{L}-4 \gamma^{2} \bar{\theta} \nu_{H} \nu_{L}+4 \nu_{H}^{2} \nu_{L}\right)}{16\left(4 \nu_{H}-\gamma^{2} \nu_{L}\right)^{2}} \\
& +\frac{(\gamma-2)^{2} \nu_{H}^{2}\left(-4 \gamma \nu_{H}^{2} \nu_{L} \gamma^{2} \nu_{H}^{2} \nu_{L}-16 \gamma \bar{\theta} \nu_{L}^{2}-4 \nu_{H} \nu_{L}^{2}+4 \gamma \nu_{H} \nu_{L}^{2}+\gamma^{2} \nu_{H} \nu_{L}^{2}+4 \gamma \nu_{L}^{3}-\gamma^{2} \nu_{L}^{3}\right)}{16\left(4 \nu_{H}-\gamma^{2} \nu_{L}\right)^{2}}
\end{aligned}
$$

14 If we introduce the restriction $\nu_{H}=\nu_{L}$ in the expressions of input prices we obtain $w_{H}=w_{L}=0$ 
The downstream monopolist chooses qualities in order to maximize $\pi_{H L}$. Deriving the FOCs, for $\gamma=0$ the chosen qualities are $\nu_{H}=\frac{4}{5} \bar{\theta}$ and $\nu_{L}=\frac{1}{2} \nu_{H}$. For $\gamma \geq \frac{2}{5} \nu_{H}=\nu_{L}=\frac{2}{3} \bar{\theta}$.

Proposition 7 Under Cournot competition and variable costs of quality improvement, the degree of product differentiation that a downstream monopolist choose reduces as the upstream bargaining power increases. No differentiation emerges whenever $\gamma \geq \frac{2}{5}$.

Proof Appendix.

The downstream merger increases the product interdependence, and we have seen how the new entity prefers to reduce the low quality good more than the high quality one. For the merging firm is more profitable to reduce the quantity of the low quality good, and this leads to a reduction in the quality of such good, whereas the level of the high quality one will be enhanced. Thus, for low values of $\gamma$, the degree of product differentiation increases with the downstream merger. In fact, for $\gamma=0$, the degree of product differentiation is the greatest of all the analyzed cases under Cournot competition (see Table 1 in the Appendix). However, as $\gamma$ increases, input prices also increase, and the downstream monopolist has a new incentive to close the quality of its products: to reduce such input prices by producing similar qualities, given that the lower the differentiation the more elastic the input demands. So, after the merger, the downstream monopolist faces a trade off: reducing the final output to increase final prices (it leads to a higher differentiation as the low quality production is reduced strongly), or choosing closer qualities to obtain lower input prices. In the case of independent upstream and downstream firms, we have seen how differentiation decreases with $\gamma$, although an scenario of no-differentiation only emerges for $\gamma=1$. But after the downstream merger, there exists an extra incentive to choose closer qualities, to curb the market power of input suppliers, and no-differentiation will emerge for lower values of $\gamma$, precisely for $\gamma \geq \frac{2}{5}$.

\subsection{Profitability of the downstream merger}

The downstream merger will be successful whenever the joint profits are greater than individually:

$$
\pi_{H L}>\pi_{H}+\pi_{L}
$$


By using equations [35], [36] and [75], the inequality of equation [76] always holds, and it can be summarized in the following proposition,

Proposition 8 Under Cournot competition and variable costs of quality improvement, a downstream merger is always profitable, whatever the distribution of the bargaining power in the vertical industry.

Proof Appendix

In proposition 6 , it was shown how the existence of a downstream monopolist implies lower input prices, as input demands become more elastic. This coordination leads to the profitability of the merger, for any value of $\gamma$.

\subsection{Some numerical examples}

An important result reported in table 1 in the Appendix is that the downstream monopolist does not differentiate its products for $\gamma \geq \frac{2}{5}$, as input prices fall to their marginal costs for that value. The chosen qualities for $\gamma \geq \frac{2}{5}$ coincides with those chosen for $\gamma=1$ when all firms act independently and downstream firms compete in quantities. For $\gamma=0$, the degree of product differentiation is the maximum of all the analyzed cases in a Cournot fashion. Therefore, the respective final prices are also the maximum and minimum obtained. Final output falls due to the downstream merger, being the reduction of the low quality good more important. We saw how the merging firm prefers to reduce the production of such good. The profitability of the downstream merger holds for all the analyzed values of $\gamma$, and the profits of the monopolist reduce with the upstream bargaining power. The level of the indifferent consumers increases, and regardless of the increase of producer surplus, social welfare decreases by the reduction of consumer surplus. Another interesting result is that for values of $\gamma>\frac{4}{5}$, social welfare increases with the merger. When input suppliers enjoy high levels of market power, input prices are also high, and a downstream merger pushes them down to their marginal cost. This important reduction is transmitted to consumers through lower final prices and higher levels of production, countervailing the negative effects of a downstream monopoly. Therefore, in those markets where there exists 
an important upstream market power, a downstream monopoly would improve the situation of consumers and producers by curbing the market power of the input suppliers.

\section{Conclusions}

Several articles in the literature have studied quality choice under different hypotheses at the market stage. In this paper, I have introduced an upstream segment to analyze how the distribution of the bargaining power between upstream and downstream firms affects the degree of product differentiation chosen by the latter. To this purpose, I have used the article of Motta (1993) as a benchmark, where downstream firms choose qualities in absence of upstream firms. The main finding of this paper is to show that the presence of upstream firms affects the way in which downstream firms differentiate their products. Particularly, the higher the upstream bargaining power, the lower the degree of product differentiation. Input suppliers and downstream firms are tied in a bilateral monopoly, and given that the former do not internalize all the effects derived from their input prices, these input prices are going to depend on both qualities, affecting the final decision about differentiation. My results only contradict Motta's (1993) when competition is à la Cournot and upstream firms have all the bargaining power, given that in this case no differentiation emerges. For the rest of analyzed cases, firms always choose to differentiate their goods, being higher the degree of product differentiation when firms compete in prices, anticipating the fiercer competition in the final market. As in Motta (1993), social welfare is also maximized in the Bertrand setting, and it is always lower with upstream presence. As upstream firms enhance their bargaining position, input prices increase, to the detriment of downstream firms, consumers and social welfare. The uncovered market becomes bigger as the bargaining power of input suppliers improves. This is due to the fact that downstream firms choose closer qualities and final prices go up. The effects of an upstream merger have been also analyzed. In this case, as input suppliers coordinate their actions, they are going to internalize all the effects that input prices 
have on rivals. Thus, input prices are not going to depend on the quality of the rival anymore, not affecting the degree of product differentiation. Upstream coordination implies higher input prices and lower social welfare. Furthermore, even though input prices do not affect differentiation, the size of the uncovered market increases through higher final prices. Then, no positive effects seem to derive from an upstream merger.

Another interesting result emerges when downstream firms become a monopoly: no differentiation is chosen unless input suppliers have sufficiently low bargaining power. A downstream monopolist has the possibility of increasing the production of one good at the expense of the other, forcing input suppliers to set lower prices. Of course, this replacing between goods is easier when goods are not differentiated, and that is what the monopolist is going to choose: no differentiation. This pushes input prices to marginal cost, and whenever input prices areo high enough before the merger, such reduction is transmitted to consumers through lower final prices and a higher production. Therefore, it is shown that a downstream monopolist can enhance social welfare.

The analysis in this model extends to Bertrand and Cournot competition, assuming variable costs of quality improvement. On the other hand, negotiations between input suppliers and downstream firms has been modelled as a generalized Nash bargaining problem. As far as upstream firms presence affects the quality choice due to a coordination problem, I do not think that assuming fixed costs of quality improvement changes the main result of this article. However, the way in which negotiations take place could modify the finding that an upstream monopolist does not affect the quality choice. Both questions remain for future research. 


\title{
Appendix
}

\author{
TABLE $^{15} 1$
}

TABLE 1

EQUILIBRIUM VALUES UNDER DIFFERENT MARKET STRUCTURES FOR $\theta=5$

Independet Firms $\quad$ Upstream Monopolist Downstream Monopolist

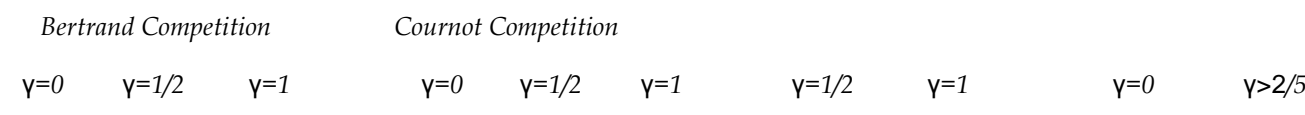

\begin{tabular}{|c|c|c|c|c|c|c|c|c|c|c|}
\hline$v_{H}$ & 4,0976 & 4,0948 & 4,0231 & 3,6905 & 3,5841 & 3,3333 & 3,6905 & 3,6905 & 4 & 3,3333 \\
\hline$V_{L}$ & 1,9936 & 2,1142 & 2,3381 & 2,9279 & 3,0607 & 3,3333 & 2,9279 & 2,9279 & 2 & 3,3333 \\
\hline $\mathrm{V}_{\mathrm{H}-} \mathrm{V}_{\mathrm{L}}$ & 2,104 & 1,9806 & 1,685 & 0,7626 & 0,5234 & 0 & 0,7626 & 0,7626 & 2 & 0 \\
\hline $\mathrm{PH}_{\mathrm{H}}$ & 11,3328 & 12,5256 & 13,5299 & 10,8427 & 11,5067 & 11,7284 & 12,7451 & 14,6475 & 14 & 11,1111 \\
\hline$P_{L}$ & 3,7505 & 4,9463 & 6,6999 & 7,8631 & 9,377 & 11,7284 & 9,5571 & 11,2512 & 6 & 11,1111 \\
\hline $\mathrm{I}_{\mathrm{H}}=\mathrm{qH}_{\mathrm{H}}$ & 1,3962 & 1,1731 & 0,9464 & 1,0928 & 0,9305 & 0,7407 & 0,8196 & 0,5464 & 1 & 0,8333 \\
\hline $\mathrm{IL}=\mathrm{qL}$ & 1,7225 & 1,4873 & 1,188 & 1,2216 & 1,0058 & 0,7407 & 0,9162 & 0,6108 & 1 & 0,8333 \\
\hline$\pi_{H}$ & 4,1016 & 2,7258 & 1,5094 & 4,4071 & 3,1034 & 1,829 & 2,479 & 1,1018 & 10 & 9,2593 \\
\hline$\Pi_{L}$ & 3,0373 & 2,2621 & 1,3821 & 4,3696 & 3,0966 & 1,829 & 2,4579 & 1,0924 & & \\
\hline$\pi^{\mathrm{H}}$ & 0 & 2,1333 & 3,6399 & 0 & 1,6273 & 2,7435 & 4,757 & 6,3427 & 0 & 0 \\
\hline$\pi^{\mathrm{L}}$ & 0 & 1,7705 & 3,3302 & 0 & 1,6237 & 2,7435 & & & 0 & 0 \\
\hline$w_{H}$ & 0 & 1,8185 & 3,8427 & 0 & 1,7487 & 3,7037 & 2,9106 & 5,8213 & 0 & 0 \\
\hline$w_{L}$ & 0 & 1,1904 & 2,8032 & 0 & 1,6143 & 3,7037 & 2,5883 & 5,1766 & 0 & 0 \\
\hline$\theta_{\llcorner\varnothing}$ & 1,8813 & 2,3395 & 2,8655 & 2,6856 & 3,0636 & 3,5185 & 3,2642 & 3,8428 & 3 & 3,3333 \\
\hline$\theta_{\mathrm{HL}}$ & 3,6038 & 3,8269 & 4,0535 & 3,9072 & 4,0695 & - & 4,1804 & 4,4536 & 4 & - \\
\hline CS & 11,7463 & 8,8452 & 6,0808 & 8,297 & 5,9648 & 3,658 & 4,6671 & 2,0743 & 5 & 4,6296 \\
\hline PS & 7,1389 & 8,8918 & 9,8586 & 8,7766 & 9,451 & 9,145 & 9,6938 & 8,5368 & 10 & 9,2593 \\
\hline sw & 18,8852 & 17,737 & 15,9394 & 17,0736 & 15,4158 & 12,803 & 14,3609 & 10,6111 & 15 & 13,8889 \\
\hline
\end{tabular}

15 CS, PS and SW represent Consumer Surplus, Producer Surplus and Social Welfare respectively. Following Motta (1993), the consumer surplus has been computed: $\int_{\theta_{L \varnothing} L}^{\theta_{H}}\left(\theta \nu_{L}-p_{L}\right) d \theta+\int_{\theta_{H L}}^{\bar{\theta}}\left(\theta \nu_{H}-p_{H}\right) d \theta$

For $\gamma=0$, the case of independent firms competing à la Cournot coincides with the case of an upstream monopolist

For simplicity, I assign the profits of the monopolist to the high quality firm. 


\section{Proof of Proposition 1}

The chosen qualities, under Cournot competition, for $\gamma=0$ and $\gamma=1$ have been performed by using the software Mathematica ${ }^{16}$. Second order conditions are locally met. Leapfrogging is never a profitable option. In this setting, $\left(\nu_{L}, \nu_{H}, \gamma\right)=(0.585576 \bar{\theta}, 0.738096 \bar{\theta}, 0)$ and $\left(\nu_{L}, \nu_{H}, \gamma\right)=$ $\left(\frac{2}{3} \bar{\theta}, \frac{2}{3} \bar{\theta}, 1\right)$ constitute an equilibrium. Given that $\nu_{L} \leq \nu_{H}$, this relation can be stated as $\nu_{L} k=\nu_{H}$ with $k \geq 1$. I solve the system:

$$
\left\{\begin{array}{l}
\frac{\partial \pi_{H}}{\partial \nu_{H}}=0 \\
\frac{\partial \pi_{L}}{\partial \nu_{L}}=0
\end{array}\right\}
$$

by using $\nu_{L} k=\nu_{H}$, and obtaining $k$ as a function of $\gamma, k=f(\gamma)$. Finally it can be proved that $\frac{\partial k(\gamma)}{\partial \gamma}<0$.

Proof of Proposition 2 The proof is the same that the one used for proposition 1.

\section{Proof of Proposition 3}

The analysis carried out by the software Mathematica (Wolfram) confirms that $w_{i}^{U M}>w_{i} i=H, L$ for $\gamma \in[0,1], \theta \geq 0$ and $0 \leq \nu_{L} \leq \nu_{H}$. A Mathematica file with this result is available upon request.

\section{Proof of Proposition 5}

Given that under upstream coordination, the chosen qualities are always $\nu_{L}=0.585576 \bar{\theta}, \nu_{H}=$ $0.738096 \bar{\theta}, \pi^{H L}$ has been performed with those qualities. When upstream firms are independent $\left(\nu_{L}, \nu_{H}, \gamma\right)=(0.585576 \bar{\theta}, 0.738096 \bar{\theta}, 0)$ and $\left(\nu_{L}, \nu_{H}, \gamma\right)=\left(\frac{2}{3} \bar{\theta}, \frac{2}{3} \bar{\theta}, 1\right)$ constitute an equilibrium. I use the relation $\nu_{L} k=\nu_{H}$ with $k \geq 1$. According to Proposition $1, k$ reduces with $\gamma$. Thus, $k \in[1,1.26]$. I check the profitability of the merger for $\gamma \in[0,1], \theta \geq 0$ and $k \in[1,1.26]$. The analysis carried out by the software Mathematica (Wolfram) confirms that $\pi^{H L}>\pi^{H}+\pi^{L}$ for those values. A Mathematica file with this result is available upon request.

\section{Proof of Proposition 6}

The analysis carried out by the software Mathematica (Wolfram) confirms that $w_{i}^{D M}<w_{i} i=H, L$ for $\gamma \in[0,1], \theta \geq 0$ and $0 \leq \nu_{L} \leq \nu_{H}$. A Mathematica file with this result is available upon request.

Proof of Proposition 7 The proof is the same that the one used for proposition 1.

\section{Proof of Proposition 8}

When downstream firms are independent $\left(\nu_{L}, \nu_{H}, \gamma\right)=(0.585576 \bar{\theta}, 0.738096 \bar{\theta}, 0)$ and $\left(\nu_{L}, \nu_{H}, \gamma\right)=$ $\left(\frac{2}{3} \bar{\theta}, \frac{2}{3} \bar{\theta}, 1\right)$ constitute an equilibrium. When downstream firms merge $\left(\nu_{L}, \nu_{H}, \gamma\right)=\left(\frac{2}{5} \bar{\theta}, \frac{4}{5} \bar{\theta}, 0\right)$ and $\left(\nu_{L}, \nu_{H}, \gamma\right)=\left(\frac{2}{3} \bar{\theta}, \frac{2}{3} \bar{\theta}, 1\right)$ constitute an equilibrium. I use the relation $\nu_{L} k=\nu_{H}$ with $k \geq 1$. According to Proposition $7, k$ reduces with $\gamma$. Thus, $k \in[1,2]$. I check the profitability of the merger for $\gamma \in[0,1], \theta \geq 0$ and $k \in[1,2]$. The analysis carried out by the software Mathematica (Wolfram) confirms that $\pi_{H L}>\pi_{H}+\pi_{L}$ for those values. A Mathematica file with this result is available upon request.

\footnotetext{
16 A Mathematica file is available upon request.
} 


\section{References}

[1] Bonanno, G., (1986), Vertical differentiation with Cournot competition, Economic Notes, 15, pp. 68-91.

[2] Caprice, S. (2006). Multilateral vertical contracting with an alternative supply: the welfare effects of a ban on price discrimination. Review of Industrial Organization 28, pp. 63-80.

[3] Champsaur, P. and Rochet, J. (1989), Multiproduct duopolists, Econometrica, 57, pp. 533557.

[4] Chen, Z. (2003), Dominant retailers and the countervailing-power hypothesis. RAND Journal of Economics 34, pp. 612-625.

[5] Cremer, J., Riordan, M.H. (1987). On governing multilateral transactions with bilateral contracts. Rand Journal of Economics 18, pp. 436-451.

[6] Dobson, P., Waterson, M. (1997). Countervailing power and consumer prices. Economic Journal 107, pp. 418-430.

[7] Gabszewicz, J. and Thisse, J. (1979), Price competition, quality and income disparities, Journal of Economic Theory, 20, pp. 340-359.

[8] Horn, H. and Wolinsky, A. (1988), Bilateral monopolies and incentives for merger, Rand Journal of Economics, 19, pp. 408-419

[9] Inderst, R., Shaffer, G. (2007). Retail mergers, buyer power and product variety. Economic Journal 117, pp- 45-67.

[10] Ireland, N. (1987), Product differentiation and non-price competition, Basil Blackwell

[11] Lommerud, K., Straume, O. and Sorgard, L. (2003), Downstream merger with upstream market power, European Economic Review, 49, pp. 717-743

[12] Milliou, C. and Petrakis, E. (2007), Upstream horizontal mergers, vertical contracts, and bargaining, International Journal of Industrial Organization, 25, pp. 963-987

[13] Motta, M. (1993), Endogenous quality choice: price vs. quantity competition, The Journal of Industrial Economics, vol. 41, No. 2, pp. 113-131

[14] Mussa, M. and Rosen, S. (1978), Monopoly and product quality, Journal of Economic Theory, 18, pp. $301-317$

[15] Peoples, J., Hekmat, A. and Moini, A.H. (1993). Corporate mergers and union wage premium. Journal of Economics and Finance, Vol. 17 pp. 65-75

[16] Scarpa, C. (1998), Minimum quality standards with more than two firms, International Journal of Industrial Organization, 16, pp.665-676

[17] Symeonidis, G. (2008). Downstream competition, bargaining and welfare. Journal of Economics and Management Strategy 17, pp. 247-270

[18] Symeonidis, G. (2010). Downstream merger and welfare in a bilateral oligopoly. International Journal of Industrial Organization 28, pp. 230-243

[19] von Ungern-Sternberg, T. (1996), Countervailing power revisited. International Journal of Industrial Organization 14, pp. 507-519 


\section{PUBLISHED ISSUES *}

WP-AD 2010-10 "Tax evasion as a global game (TEGG) in the laboratory"

M. Sánchez-Villalba. February 2010.

WP-AD 2010-11 "The effects of the tax system on education decisions and welfare"

L.A. Viianto. March 2010.

WP-AD 2010-12 "The pecuniary and non-pecuniary costs of job displacement. The risky job of getting back to work"

R. Leombruni, T. Razzolini, F. Serti. March 2010.

WP-AD 2010-13 "Self-interest and justice principles"

I. Rodríguez-Lara, L. Moreno-Garrido. March 2010.

WP-AD 2010-14 "On spatial equilibria in a social interaction model”

P. Mossay, P.M. Picard. March 2010.

WP-AD 2010-15 "Noncooperative justifications for old bankruptcy rules"

J.M. Jiménez-Gómez. March 2010.

WP-AD 2010-16 "Anthropometry and socioeconomics in the couple: evidence from the PSID"

S. Oreffice, C. Quintana-Domeque. April 2010.

WP-AD 2010-17 "Differentiated social interactions in the US schooling race gap"

L.J. Hall. April 2010.

WP-AD 2010-18 "Things that make us different: analysis of variance in the use of time"

J. González Chapela. April 2010.

WP-AD 2010-19 "The role of program quality and publicly-owned platforms in the free to air broadcasting industry"

M. González-Maestre, F. Martínez-Sánchez. June 2010.

WP-AD 2010-20 "Direct pricing of retail payment methods: Norway vs. US"

F. Callado, J. Hromcová, N. Utrero. June 2010.

WP-AD 2010-21 "Sexual orientation and household savings. Do homosexual couples save more?

B. Negrusa, S. Oreffice. June 2010.

WP-AD 2010-22 "The interaction of minimum wage and severance payments in a frictional labor market: theory and estimation"

C. Silva. June 2010.

WP-AD 2010-23 "Fatter attraction: anthropometric and socioeconomic matching on the marriage market"

P.A. Chiappori, S. Oreffice, C. Quintana-Domeque. June 2010.

WP-AD 2010-24 "Consumption, liquidity and the cross-sectional variation of expected returns"

E. Márquez, B. Nieto, G. Rubio. July 2010.

WP-AD 2010-25 "Limited memory can be beneficial for the evolution of cooperation"

G. Horváth, J. Kovárík, F. Mengel. July 2010.

WP-AD 2010-26 "Competition, product and process innovation: an empirical analysis" C.D. Santos. July 2010.

WP-AD 2010-27 "A new prospect of additivity in bankruptcy problems"

J. Alcalde, M.C. Marco-Gil, J.A. Silva. July 2010.

WP-AD 2010-28 "Diseases, infection dynamics and development"

S. Chakraborty, C. Papageorgiou, F. Pérez Sebastián. September 2010.

WP-AD 2010-29 "Why people reach intermediate agreements? Axiomatic and strategic justification" J.M. Jiménez-Gómez. September 2010.

WP-AD 2010-30 “Mobbing and workers' health: an empirical analysis for Spain”

M.A. Carnero, B. Martínez, R. Sánchez-Mangas. September 2010.

WP-AD 2010-31 "Downstream mergers in a vertically differentiated unionized oligopoly"

A. Mesa-Sánchez. October 2010.

WP-AD 2010-32 "Endogenous quality choice under upstream market power"

B. Mesa-Sánchez. November 2010.

WP-AD 2010-33 "Itemised deductions: a device to reduce tax evasion"

A. Piolatto. November 2010.

\footnotetext{
* Please contact Ivie's Publications Department to obtain a list of publications previous to WP-AD 2010-10.
} 


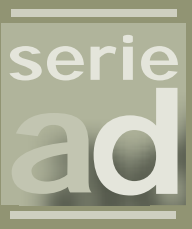

\section{I vie}

Guardia Civil, 22 - Esc. 2, 1 o

46020 Valencia - Spain

Phone: +34963190050

Fax: +34 963190055

Department of Economics

University of Alicante

Campus San Vicente del Raspeig

03071 Alicante - Spain

Phone: +34965 903563

Fax: +34965903898

Website: www.ivie.es

E-mail: publicaciones@ivie.es 